\title{
Pre-service Special and General Educators' Perceptions of Bullying
}

\author{
Chad A. Rose \\ University of Missouri \\ Lisa E. Monda-Amaya \\ University of Illinois \\ June L. Preast \\ University of Alabama
}

\begin{abstract}
Successful approaches for decreasing bullying among youth hinge on the competence of teachers, yet teachers' perceptions of bullying often differ from those of students. This study used the Bullying Perceptions ScaleRevised to investigate perceptions of 221 pre-service teachers at a large university in the midwestern United States. Results suggested that preservice teachers believe all topographies of bullying warrant intervention. Additionally, when asked to recall an episode of bullying, pre-service teachers typically recalled a scenario that involved verbal bullying (84.0\%), occurred in the classroom (43.6\%), in elementary (44.0\%) or middle school (39.6\%), when teachers were present (50.2\%). The findings imply a need for increased focus on bully identification and prevention in the teacher preparation curriculum.
\end{abstract}

How teachers understand and perceive student behaviour influences their reactions and interventions when responding to aggression. In particular, the perceptions and understanding teachers have regarding bullying shapes how bullying is addressed in schools and classrooms. All teachers enter their pre-service education program with a continuum of prior knowledge, which in part dictates their training and future practice. For example, Ruttan, McDonnell, and Nordgren (2015) examined the effects of prior experience on compassion for emotional distress. Individuals who had and had not 
experienced bullying were surveyed on their compassion for a bullying victim and their tolerance of that victim's response to bullying. The scenarios presented involved the bullying victim responding with bullying-induced failure (e.g., aggression) or with endurance (i.e., managing-to-endure; Ruttan, et al., 2015). The study found that those with previous experience of bullying were more tolerant and compassionate toward an individual who responded to bullying with endurance than toward an individual who responded to bullying with aggression or perceived failure (Ruttan et al., 2015). In contrast, the participants with no previous experience of bullying displayed more compassion toward the victim of bullying than those who previously experienced bullying when the individual responded with aggression (Ruttan et al., 2015). Therefore, it is crucial to evaluate pre-service teachers' understanding of, and responses to, bullying in order to develop more targeted and appropriate approaches to prevention.

\section{Defining the Bullying Dynamic}

Defining bullying has been a topic of recent debate; however, the U.S. Centers for Disease Control and Prevention (CDC) defines it as "any unwanted aggressive behavior(s) by another youth or group of youths who are not siblings or current dating partners that involves an observed or perceived power imbalance and is repeated multiple times or is highly likely to be repeated" (Gladden, Vivolo-Kantor, Hamburger, \& Lumpkin, 2014, p. 70). According to a recent, large-scale cross-sectional study ( $n=15,185$ students), $41 \%$ of elementary, middle, and high school youth reported to be frequently involved in the bullying dynamic as victims $(23 \%)$, bullies $(8 \%)$, and/or bullyvictims (9\%; Bradshaw, Sawyer, and O'Brennan, 2007). When disability status is considered, Rose and Gage (2017) reported that students with disabilities are disproportionately identified as both perpetrators and victims over time, when compared to their peers without disabilities.

The social ecology that maintains bullying has direct implications for the socialemotional development of school-aged youth (Hong \& Espelage, 2012). Teachers can function as the intermediary between school and family by helping students develop and improve their social competence, offering social skills instruction and supports, providing verbal and non-verbal communication, and modeling and reinforcing socially appropriate behaviours. Teachers play a fundamental role in structuring and supporting the behaviours of their students through student-teacher relationships, classroom climate and management, and scaffolding of student social development (Farmer, Lines, \& Hamm, 2011). Teachers have the ability to recognize that bullying may be grounded in the social construction of the school (e.g., school climate, school belonging, student involvement), and can be instrumental in implementing school and classroom bully prevention procedures (Lewis \& Rose, 2013; Rose \& Monda-Amaya, 2012; Ross \& Horner, 2009). Unfortunately, teachers often (a) underestimate the prevalence of bullying (Bradshaw et al., 2007), (b) misidentify bullies and victims (Bradshaw et al., 2007; van Roekel, Scholte, \& Didden, 2010), and (c) misinterpret aggressive scenarios or situations (Beran, 2006; van Roekel et al., 2010).

In regard to identifying individuals involved in bullying situations, it is important to reiterate that students with disabilities are disproportionately represented as perpetrators, victims, and bully-victims (Farmer et al., 2012; Rose, Monda-Amaya, \& Espelage, 2011). 
It has been argued that disability severity, disability characteristics, and school factors may contribute to the disproportionality of students with disabilities in bullying (Rose et al., 2011). Specifically, students with high incidence disabilities reported higher levels of victimization in inclusive settings, whereas students with low incidence disabilities reported higher levels of victimization in restrictive settings (Rose et al., 2015). Due to the disproportionate involvement of students with disabilities in bullying, disability status may influence teacher perceptions of bullying.

While characteristics and types of bullying are relatively consistent in the literature, students and teachers often perceive bullying quite differently. Conceivably, differences between these groups could be attributed to maturity and experience, given that students restrict their definitions to more direct forms of aggression and teachers often consider both direct and indirect forms of aggression as well as underlying contextual factors (Maunder, Harrop, \& Tattersall, 2010; Naylor, Cowie, Cossin, de Bettencourt, \& Lemme, 2006). It should also be noted that bullying is a subset of peer aggression: Bullying is considered proactive aggression, and traditional forms of aggressive behaviours (e.g., fighting) are considered reactive (Rose \& Espelage, 2012). Consequently, perceptions of these constructs may overlap due to individual perceptions. The defining characteristics of bullying (e.g., proactive aggression) should dictate how teachers classify acts of aggression and how they identify participants, yet research has suggested that the interpretations are quite subjective. Bauman and Del Rio (2006), for example, found that teachers generally identified physical threats or abuse as bullying regardless of the characteristics of the situation. Given these discrepancies in categorizing bullying scenarios and the identification of participants, it becomes necessary to investigate how and why teachers make such decisions.

\section{Perceptions of Bullying}

The perceptions that students and teachers develop have the potential to be influenced not only by the school environment, but also by other social interactions with students and teachers. Bronfenbrenner's ecological systems theory $(1977,1986)$ stated that an individual's behaviours and development are influenced by the complex interactions of social and physical systems in which the individual is situated. For example, both student behaviour and teacher perceptions and response skills are influenced by direct and indirect interactions with various stakeholders and environmental systems, including parents or custodians, students, teachers, school environment and structure, community, and societal perceptions (Hong \& Espelage, 2012). Social learning theory (Bandura, 1977) asserted that individuals engage in behaviour learned from the observation of others. Therefore, a teacher's perception of bullying and response skills, for instance, could be influenced by the responses of the teacher's colleagues and administration.

Fundamentally, bullying involves complex social interactions between victim(s), perpetrator(s), and bystander(s) (Hong \& Espelage, 2012); but the roles associated with bullying are fluid, with individuals moving in and out of roles (i.e., bully, victim, bystander) based on time and context (Hong \& Espelage, 2012; Rose et al., 2015; Salmivalli, 2010). For example, Gumpel, Zioni-Koren, and Bekerman (2014) argued that 
role fluctuation may be, in part, a function of classroom management styles and established social context, making it possible for an individual to switch roles within a single observed episode. Unfortunately, even if role fluctuation is grounded in classroom management and social contexts, teachers tend to categorize acts of bullying based on their own previous experiences and on their understanding of the characteristics of the observed behaviours. Interestingly, evidence suggests that teachers can adequately identify bullying situations when given pre-determined scenarios, but may overgeneralize acts of direct peer aggression (physical or direct verbal) that do not necessarily parallel the defining characteristics of bullying (i.e., imbalance of power, intent to cause harm, repetition, unequal levels of affect; Hazler, Miller, Carney, \& Green, 2001).

The content and knowledge gained from teacher education programs vary depending on the programmatic track of general education or special education preparation. Pre-service teachers enrolled in special education preparation programs commonly receive more course instruction in differentiated instruction and in behaviour and classroom management, whereas general education preparation programs typically focus on content knowledge (Brownell, Ross, Colón, \& McCallum, 2005). Subsequently, the specialized training associated with the special education certification may uniquely qualify special educators to recognize the diverse needs and risk factors related to certain populations of students and topographies of behaviour (Syriopoulou-Delli, Cassimos, Tripsianis, \& Polychronopoulou, 2012).

From a student's perspective, reluctance to inform teachers about bullying experiences may occur for a variety of reasons: (a) fear of exacerbating the problem (Athanasiades \& Deliyanni-Kouimtzis, 2010; Newman \& Murray, 2005), (b) concern that teachers may not believe them or will be unable to provide assistance (Brendtro, Ness, \& Mitchell, 2001; Miller, Beane, \& Kraus, 1998; Newman \& Murray, 2005; Sharp \& Smith, 1994; Walker, Colvin, \& Ramsey, 1995), or (c) belief that they can resolve the conflict independently (Miller et al., 1998). Additionally, teachers' inconsistent interventions and passivity in responding to bully perpetrators may cause students who are victimized to believe teachers are uncaring or unable to protect them (Athanasiades \& Deliyanni-Kouimtzis, 2010; Yoon \& Kerber, 2003).

While a majority of teachers view bullying as a serious problem in their schools (Nicolaides, Toda, \& Smith, 2002), they may not view all types of bullying as disconcerting. For example, teachers rate threats of physical aggression or perpetration of physical abuse as the most serious type of bullying (Bauman \& Del Rio, 2006; Ellis \& Shute, 2007; Hazler et al., 2001; Newman \& Murray, 2005) - a view that may result from a teacher's moral obligation to intervene in potentially harmful situations (Bauman \& Del Rio, 2006; Ellis \& Shute, 2007). Teachers prioritize attention to physical aggression rather than to verbal or relational aggression, even though victims of all three experience negative long-term outcomes (Crosby, Oehler, \& Capaccioli, 2010; Maunder et al., 2010; Yoon \& Kerber, 2003).

Few studies have examined the amount of training received by pre-service teachers on bullying in schools; however, some studies have investigated teacher and pre-service teacher perceptions of bullying. For example, Nicolaides, Toda, and Smith (2002) surveyed pre-service teachers about their perceptions of bullying, as well as about the training they received on bullying. Results suggested that the majority of those surveyed 
considered information on school bullying to be essential to their teacher training. In particular, pre-service teachers reported that information on how to talk with bullies and victims would be of most value to them (Nicolaides et al., 2002)

Ultimately, teacher perceptions of bullying determine how they classify and recognize peer aggression and bullying within their schools. Once a teacher identifies peer aggression, they then rank the severity of the aggression to subsequently determine their willingness to intervene.

Intervention strategies employed by educators often are based on their perceptions of the seriousness of the incident (Ellis \& Shute, 2007; Kochenderfer-Ladd \& Pelletier, 2008). Teachers believe help should be sought and provided when physical harm is threatened or perpetrated (Newman \& Murray, 2005). To assess individualized intervention efforts, Kochenderfer-Ladd and Pelletier (2008) investigated the influence of teacher classroom management strategies for decreasing bullying. Following a survey of 34 elementary school teachers, the researchers found that the strategies the teachers used in their classrooms to manage behaviours were related to their varying attitudes and beliefs about bullying.

\section{Purpose}

One crucial first step in decreasing bullying perpetration and victimization rates among school-aged youth is to determine how educators perceive the problem and how they subsequently intervene. Ultimately, teachers must be aware of their personal conceptualization of bullying and of how their prior experiences may have influenced their understanding of this phenomenon. They must be able to self-evaluate their perceptions of the prevalence of bullying, their willingness to intervene in specific situations, and their conceptualization of the severity of specific types of bullying (e.g., physical, verbal, indirect, sexual). While these areas are germane to the entire teaching profession, it is important to assess these thoughts and behaviours at the pre-service level, so universities can embed aspects of bullying prevention throughout licensure preparation. Unfortunately, few studies have investigated pre-service teacher perceptions; this study attempts to fill this gap in the literature by assessing pre-service teachers' (a) definitions of bullying, (b) perceptions of the impact of a previous bullying experience on perception and definitions, (c) ratings of severity and willingness to intervene in specific bullying scenarios, and (d) interpretations of current bully prevention practices. Ultimately, by gaining a better understanding of how pre-service teachers perceive the bullying dynamic, we can begin to examine more closely the differences between student and teacher interpretations of bullying, develop more effective school- and classroom-based interventions, and better prepare teachers for the classroom environment.

\section{Method}

\section{Participants}

Participants were 221 pre-service teachers from one large university in the midwestern United States, enrolled in teacher preparation programs in general education $(n=179)$ and special education $(n=42)$ at the third year, fourth year, or graduate level. General education participants included 116 elementary and 63 secondary (English, 
Foreign Language, and Agriculture) education majors. The mean age for both elementary and secondary majors was 21.68 years (range $=20-29$ years, $S D=1.19$ years). All general education participants were enrolled in a state-required special education course examining issues, methods, and strategies in working with students with special needs in the general education classroom. This course included instruction on service delivery models, roles of teachers and related service providers, student assessment, and adapting and individualizing curriculum and instruction, as well as program evaluation. The course also introduced students to concepts around managing problem behaviours including a brief 30-minute lecture on bullying, which occurred after the study was conducted. During the semester in which the study was conducted, the secondary respondents participated in one 8-week observation experience; previously there had been no other required classroom experiences. The observation experience did not require significant interaction with secondary students in the classroom. The elementary participants, on the other hand, were engaged in their first practicum experience during the semester in which the research took place. Through this experience they worked with classroom teachers, but had no requirements in which they were solely responsible for instruction.

The 42 special education participants were enrolled in the pre-service program in special education. The mean age of the special education majors was 21.17 years. Students were surveyed in their supervised practicum seminar course in special education. This seminar was a weekly 2-hour course for discussing their practicum and clinical experiences and for delving into issues related to students with disabilities. Although this class was geared toward participants' clinical experiences, it also included instruction on individualizing curriculum, instructional programs, student assessment, managing problem behaviours, and program evaluation. Specific demographic data for participants are provided in Table 1.

Table 1

Demographics of Respondents

\begin{tabular}{lrc}
\hline \multicolumn{1}{c}{ Variables } & $\boldsymbol{n}$ & $\%$ \\
\hline Gender & 26 & 11.6 \\
$\quad$ Male & 196 & 87.1 \\
$\quad$ Female & & \\
Certification Area & 116 & 51.6 \\
$\quad$ Elementary Education (K-8) & 63 & 28.4 \\
$\quad$ Secondary Education (Secondary English, & \\
$\quad$ Foreign Language, Agriculture; 6-12) & & \\
$\quad$ Special Education (K-12) & 42 & 18.7 \\
Pursuing a Teaching Position & & \\
$\quad$ Yes & 218 & 96.9 \\
No & 2 & 00.9 \\
\hline
\end{tabular}




\section{The Bullying Perceptions Scale-Revised}

The Bullying Perception Scale-Revised (BPS-R; Rose \& Monda-Amaya, 2008) was created following a review of the literature on constructs surrounding the bullying dynamic and after consultation with experts in the fields of bullying, challenging behaviours, and peer aggression. The BPS-R contains four sections designed to assess participants': (a) definition of bullying, (b) experiences with a specific bullying incident, (c) overall perceptions of bullying, (d) ratings of the severity of specific scenarios, and (e) willingness to intervene on those scenarios. The BPS-R was subjected to several revisions based on feedback, pilot testing, and statistical review.

Defining bullying. Definitions of bullying were assessed in Section A of the instrument, which contained a Types of Bullying subscale (physical aggression, verbal aggression, indirect aggression, and sexual aggression) and Bullying Characteristics subscale (imbalance of power, harmful intent, repeated victimization, and unequal levels of affect). Using these subscales, respondents were asked to rate how crucial the eight items were to their personal definition of bullying on a six-point Likert scale $(1=n o t$ at all critical to $6=$ absolutely critical). A Cronbach's alpha coefficient of .85 was found for the Types of Bullying subscale and .71 for the Bullying Characteristics subscale, which demonstrates acceptable internal consistency.

Personal experiences with bullying. In Section B of the survey, Personal Experience with Bully Perpetration and Victimization, respondents were given specific instructions to recall a bullying situation they experienced, engaged in, or witnessed. Participants then were asked to respond to 23 items addressing: (a) the logistics of the episode (e.g., participant demographics, type of bullying, location of the episode), (b) perceptions of the types of interventions they felt would have been most appropriate for dealing with problem (i.e., peer, teacher, school, parent or guardian, no intervention), (c) the severity of the situation, and (d) their reflections on the situation from the context of the empirical definition of bullying (imbalance of power, intent to cause harm, repeated victimization, unequal levels of effect). The logistics and intervention items were assessed through categorical variables derived from the literature. The severity and agreement items were examined using a six-point Likert scale $(1=$ not at all to $6=$ to a very great extent).

In addition to recalling a specific example of bullying, participants were asked to respond to three items that assessed their personal experience with bullying during their schooling. Items included "How often did you witness bullying while you were in school?", "How often were you victimized when you were in school?", and "How often did you engage in bully perpetration when you were in school?" These items were assessed on a six-point Likert scale $(1=$ not at all to $6=$ on a daily basis $)$. Given the specificity associated with each item in Section B, data were analyzed at the item level, thus alpha coefficients were not calculated.

Perceptions of bullying perpetration and victimization. Section $\mathrm{C}$ of the BPS-R assessed participants' perceptions of bullying across five separate constructs (i.e., practising teacher's knowledge and beliefs regarding bullying, involvement with students with disabilities, appropriateness of current school interventions, severity of bullying scenarios, and willingness to intervene in bullying scenarios). In the first part of Section 
$\mathrm{C}$, the pre-service teachers rated their general beliefs regarding perceptions of antibullying practices on a six-point Likert-scale $(1=$ not at all to $6=$ to a very great extent $)$. First, four items assessed the respondents' beliefs regarding practising teachers' knowledge and responsiveness to bullying situations (e.g., "To what extent do you believe that teachers recognize which students engage in bullying perpetration?"). Second, three items assessed the respondents' perceptions of the direct involvement of students with disabilities (e.g., "To what extent do you believe that students with disabilities are bullied more than students without disabilities?"). Third, two items assessed the respondents' perceptions of the responsibilities of the school and district around bullying (e.g., "To what extent do you believe that schools should incorporate targeted bullying interventions for students with disabilities?"). A Cronbach's alpha coefficient of .73 was found for the Teacher Recognition and Intervention in Bullying subsection, demonstrating acceptable internal consistency. Given the contextual differences between items on the Involvement of Students with Disabilities and School Intervention sections, analyses were conducted at the item level, thus alpha coefficients were not calculated.

In part two of Section C, 12 bullying scenarios were presented that were generated from actual situations obtained in data collection from a previous study in which the BPS was piloted (Rose \& Monda-Amaya, 2007). In the previous study, respondents were asked to qualitatively describe a scenario that they witnessed, experienced, or perpetrated. These qualitative scenarios were coded based on a priori decision rules, including type (i.e., physical, verbal, indirect, sexual) and evidence of adherence to the traditional definition (i.e., imbalance of power, intent to cause harm, repetition, unequal levels of affect), by the lead authors and graduate student research assistants. Following the coding, the best representation of physical, verbal, indirect, and sexual bullying were selected, resulting in 12 scenarios (i.e., 3 scenarios for each type). For example, the following scenario was generated for the BPS-R based on a real scenario described in the pilot: "During passing period, a student consistently gets his books knocked out of his hands by a group of 'popular' students. Although he tries to take alternate routes to his classroom or locker, the boys continue to follow him." The 12 scenarios developed for the BPS-R were assessed in two ways, asking pre-service teachers to rate the severity $(1=$ not severe to $6=$ extremely severe $)$ and the participants' willingness, as a future teacher, to intervene $(1=$ would not intervene to $6=$ definitely intervene $)$. A Cronbach's alpha coefficient of .88 was found for the Episode Severity Ratings subscale and .91 for the Episode Willingness to Intervene subscale, demonstrating strong internal consistency.

\section{Procedures}

Data were collected across seven courses (four elementary, one secondary, two special education) over a period of one week. In each class the researcher was introduced and read an explanatory script detailing the purpose and goals of the study. Surveys then were distributed to potential respondents along with a waiver of written consent that summarized the purpose of the study, anonymity procedures, potential risks, and withdrawal or non-participation options. Respondents were then instructed to begin the survey. The entire procedure lasted approximately 30 minutes, with the survey itself 
taking approximately 23 minutes. The survey was completely voluntary, and respondents were not compensated for their time.

A power analysis was conducted using $\mathrm{G}^{*}$ Power 3.1 (Faul, Erdfelder, Buchner, \& Lang, 2009) for MANOVA (Global Effects) for three groups of respondents across a maximum of 12 items or constructs per analysis. Given the limited effect sizes in previous pre-service teacher studies, the parameters of effect size was established at .10 with an alpha level of .05 , resulting in a total required sample of 174 to obtain a power level of 95 .

\section{Results}

\section{Defining Bullying and the Role of Students with Disabilities}

As a preliminary step, means and standard deviations were calculated to assess preservice teachers' perceptions of the importance of types of bullying (i.e., physical, verbal, indirect, sexual) and characteristics of bullying (i.e., imbalance of power, intent to cause harm, repetition, unequal levels of affect) to the general definition of bullying. Overall mean ratings for Types of Bullying and Bullying Characteristics (see Table 2) were fairly consistent and moderately high (approximately 4 out of 6 ), indicating that respondents felt each of the eight items contributed to the definition of bullying. More specifically, the overall mean on the Types of Bullying subscale was $3.97(S D=1.28)$ across the four items, with $23 \%$ of respondents reporting scores that were at least one standard deviation above the mean. Item-level descriptives revealed a range of $3.83(S D=1.81$; sexual) to $4.83(S D=1.32$; verbal). The overall mean on the Bullying Characteristics subscale was $4.55(S D=1.09)$ across the four items, with $15 \%$ of respondents reporting scores that were at least one standard deviation above the mean. Item level descriptives revealed a range of $4.26(S D=1.35$; unequal levels of affect $)$ to $4.78(S D=1.39$; intent to cause harm).

\section{Table 2}

\section{Types of Bullying and Bullying Characteristics Subscales} Means and Standard Deviations

\begin{tabular}{lccc}
\hline Characteristics & N & Mean & SD \\
\hline Verbal aggression & 225 & 4.83 & 1.32 \\
Indirect aggression & 225 & 4.11 & 1.33 \\
Physical aggression & 225 & 3.55 & 1.67 \\
Sexual aggression & 221 & 3.38 & 1.81 \\
Intent to cause emotional or physical harm to victim & 223 & 4.78 & 1.39 \\
Aggression repeated over the course of days, months, & 225 & 4.59 & 1.40 \\
$\quad$ or years & & 4.57 & 1.36 \\
Imbalance of power between bully and victim & 225 & 4.26 & 1.35 \\
\hline
\end{tabular}


To assess differences in characteristics associated with the definition of bullying, a MANOVA was conducted across the Types of Bullying subscale and the Bullying Characteristics subscale by content major (elementary, secondary, or special educators). Based on the results of the MANOVA, the three groups did not vary in how they rated their importance on the components associated with the bullying definition (Wilks' $\left.\lambda=.97, F_{(4,434)}=1.90, p=.11, \eta_{\mathrm{p}}{ }^{2}=.02\right)$. To explore these constructs further, an itemlevel MANOVA was conducted based on the eight items used to create the two constructs (i.e., Types of Bullying subscale, Bullying Characteristics subscale). The multivariate statistics proved to be significant (Wilks' $\lambda=.88, F_{(16,412)}=1.68, p<.05, \eta_{\mathrm{p}}{ }^{2}=.06$ ). Univariate statistics revealed significant differences existed on physical aggression $\left(F_{(2,213)}=3.12, p<.05, \eta_{\mathrm{p}}{ }^{2}=.03\right)$, imbalance of power $\left(F_{(2,213)}=4.27, p<.05, \eta_{\mathrm{p}}{ }^{2}=.04\right)$, and unequal levels of affect $\left(F_{(2,213)}=4.44, p<.05, \eta_{\mathrm{p}}{ }^{2}=.04\right)$. Tukey post hoc test revealed that secondary teachers reported significantly $(p<.05)$ higher scores on physical aggression $(M=3.92, \mathrm{SD}=1.76)$, imbalance of power $(M=4.89, S D=1.22)$, and unequal levels of affect $(M=4.70, S D=1.43)$ than elementary teachers $(M=3.29, S D=1.64$; $M=4.33, S D=1.39 ; M=4.12, S D=1.29$, respectively), and significantly higher scores on unequal levels of affect than special education teachers $(M=4.02, S D=1.33)$.

In addition, a MANOVA was conducted to examine perceptions of the three groups on their ratings of items related to the involvement of students with disabilities in bullying (i.e., victim, bully, or fight more often). The multivariate analysis proved to be significant (Wilks' $\lambda=.92, F_{(6,408)}=2.73, p<.05, \eta_{\mathrm{p}}{ }^{2}=.04$ ). Univariate results revealed that significant differences existed between the groups on "students with disabilities as victims" $\left(\mathrm{F}_{(2,206)}=4.19, p<.05, \eta_{\mathrm{p}}{ }^{2}=.04\right)$, "students with disabilities as perpetrators" $\left(\mathrm{F}_{(2,206)}=4.44, p<.05, \eta_{\mathrm{p}}{ }^{2}=.04\right)$, and "students with disabilities as physical aggressors" $\left(\mathrm{F}_{(2,206)}=3.51, p<.05, \eta_{\mathrm{p}}{ }^{2}=.03\right)$. Tukey post hoc test revealed that pre-service special education teachers assigned significantly higher scores $(p<.05)$ for victimization $(M=4.26, S D=1.19)$, bully perpetration $(M=2.86, S D=1.16)$, and fighting $(M=3.10$, $S D=1.23)$ than pre-service elementary teachers $(M=3.61, S D=1.26 ; M=2.36$, $S D=1.08 ; M=2.52, S D=1.16$, respectively), and higher scores of bully perpetration than pre-service secondary teachers $(M=2.24, S D=1.02)$.

\section{Influential Experiences}

In recalling a situation in which participants experienced, engaged in, or witnessed an act of bullying, respondents identified: (a) their role in the bullying situation, (b) the location of the episode, (c) the type of bullying, (d) the grade level of the participants, (e) whether an adult was present, and (f) the types of interventions that would have been most appropriate for handling the situation. For each item, respondents were given a list of choices and asked to check all that applied.

Respondents predominately reported being either a bystander $(31.6 \%)$ or adult bystander $(24.9 \%)$ in the situation. However, $24 \%$ reported being the victim and $6 \%$ reporting being the bully. The location in which the bullying behaviour occurred most often was the classroom (43.6\%), followed by the playground $(29.3 \%)$ and the cafeteria $(23.6 \%)$. The majority of respondents recalled an episode of verbal bullying $(84.0 \%)$, as opposed to physical $(25.3 \%)$, indirect $(24.9 \%)$, or sexual $(1.3 \%)$. Furthermore, the 
majority of respondents recalled an episode that occurred in either elementary $(44.0 \%)$ or middle school (39.6\%). Respondents reported that teachers were present during the incident $(50.2 \%)$ and that teacher-initiated (52.4\%) and student-initiated (40\%) interventions would have been most appropriate for the situation.

\section{Pre-service Teachers' Beliefs About Current Intervention Efforts}

To examine pre-service teachers' beliefs about current intervention efforts, a MANOVA was conducted at the item level, with the four items associated with teacher recognition of and intervention in bullying serving as dependent variables, and the preservice teacher groupings (i.e., elementary, secondary, special education) serving as the independent variable. The multivariate analysis proved to be significant (Wilks' $\lambda=.91$, $\left.F_{(8,422)}=2.56, p<.05, \eta_{\mathrm{p}}{ }^{2}=.05\right)$. Univariate results suggested that significant differences existed between the groups for "Teachers adequately intervene to prevent bullying from occurring" $\left(F_{(2,214)}=6.04, p<.01, \eta_{\mathrm{p}}{ }^{2}=.05\right)$. Tukey post hoc comparisons revealed that elementary education majors $(M=2.97, S D=1.10)$ believed that teachers intervene more often than secondary $(M=2.56, S D=.86)$ and special education $(M=2.40, S D=1.06)$ pre-service teachers.

To further investigate whether pre-service teachers believed practising teachers recognized, intervened, and provided support, the items related to responsibilities of the school and district from Section $\mathrm{C}$ were analyzed by content major to assess whether respondents varied in their beliefs and perspectives on whether schools should incorporate school-wide bully prevention programs and targeted interventions. Therefore, a MANOVA was conducted at the item level, and proved to be significant (Wilks' $\left.\lambda=.96, F_{(4,426)}=2.43, p<.05, \eta_{\mathrm{p}}{ }^{2}=.02\right)$. Univariate analyses suggested that significant differences existed between the groups on school-wide interventions $\left(F_{(2,214)}=3.07\right.$, $\left.p<.05, \eta_{\mathrm{p}}{ }^{2}=.03\right)$. Tukey post hoc comparisons revealed that special education majors $(M=5.74, S D=.63)$ believed that school-wide intervention efforts were more necessary than secondary education majors $\operatorname{did}(M=5.31, S D=1.04)$.

\section{Bullying Severity and Willingness to Intervene by Major}

To determine how pre-service teachers rated the severity of, and their willingness to intervene on, specific bullying scenarios designed to assess physical, verbal, indirect, and sexual bullying, a series of MANOVAS was conducted. Each scale contained 12 scenarios, 3 scenarios representing each type of bullying (physical, verbal, indirect, sexual). To assess group differences, four MANOVAs were conducted for: (a) item-level severity of the scenarios, (b) item-level willingness to intervene in the scenarios, (c) cluster-level severity of scenarios (i.e., physical, verbal, indirect, sexual), and (d) cluster-level willingness to intervene. MANOVAs conducted on the three groups of respondents did not differ significantly on any of the 12 items for severity (Wilks' $\lambda=.87$, $\left.F_{(24,400)}=1.24, p=.20, \eta_{\mathrm{p}}{ }^{2}=.07\right), 12$ items for willingness to intervene (Wilks' $\lambda=.85$, $F_{(24,400)}=1.38, p=.11, \eta_{\mathrm{p}}{ }^{2}=.08$ ), or the global clusters (i.e., physical, verbal, indirect, sexual) for severity (Wilks' $\lambda=.96, F_{(8,430)}=1.27, p=.26, \eta_{\mathrm{p}}{ }^{2}=.02$ ) and for willingness to intervene (Wilks' $\lambda=.96, F_{(8,430)}=1.17, p=.32, \eta_{\mathrm{p}}{ }^{2}=.02$ ). However, the overall mean scores on the clusters of scenarios revealed the following rating: sexual $(M=5.46$, 
$S D=.53)$, verbal $(M=5.17, S D=.67)$, physical $(M=5.05, S D=.65)$, and indirect bullying $(M=4.97, S D=.68)$ in order of severity. Similarly, overall mean scores on willingness to intervene were as follows: sexual $(M=5.58, S D=.59)$, verbal $(M=5.46$, $S D=.71)$, physical $(M=5.45, S D=.64)$, and indirect bullying $(M=5.23, S D=.81)$.

\section{Bullying Severity and Willingness to Intervene by Previous Experience with Bullying}

In addition to pre-service major, respondents were asked to identify prior involvement in bullying during their $\mathrm{K}-12$ education ("How often did you witness bullying while you were in school?", "How often were you victimized when you were in school?", and "How often did you engage in bully perpetration when you were in school?'). Responses were recoded into three groups: Seldom (rating of 1 or 2), Occasionally (rating of 3 or 4), or Frequently (rating of 5 or 6). Frequencies and percentages for each subgroup are presented in Table 3.

Table 3

Reported Involvement in Bullying as a Bystander, Victim, or Bully

\begin{tabular}{lccc}
\hline Respondent & $\begin{array}{c}\text { Seldom } \\
\boldsymbol{n}(\%)\end{array}$ & $\begin{array}{c}\text { Occasionally } \\
\boldsymbol{n}(\%)\end{array}$ & $\begin{array}{c}\text { Frequently } \\
\boldsymbol{n}(\%)\end{array}$ \\
\hline Bystander & $35(15.6)$ & $129(57.3)$ & $56(24.9)$ \\
Victim & $156(69.3)$ & $55(24.4)$ & $9(4.0)$ \\
Bully & $181(80.4)$ & $37(16.4)$ & $3(1.3)$ \\
\hline
\end{tabular}

To discern whether previous experiences with bullying is associated with interpretations with bullying scenarios and their willingness to intervene, a final series of MANOVAs were conducted using these experience groupings as the independent variables and the severity and willingness to intervene groupings as the dependent variables. Multivariate analyses revealed that no significant differences existed for victimization (Wilks' $\lambda=.93, F_{(16,388)}=.921, p=.55, \eta_{\mathrm{p}}{ }^{2}=.04$ ) or bullying (Wilks' $\left.\lambda=.91, F_{(16,388)}=1.17, p=.29, \eta_{\mathrm{p}}{ }^{2}=.05\right)$, but the difference was significant for bystanders (Wilks' $\lambda=.85, F_{(16,388)}=2.11, p<.01, \eta_{\mathrm{p}}{ }^{2}=.08$ ). Univariate analyses suggested that significant group differences existed for perceptions of severity of physical bullying $\left(F_{(2,201)}=5.22, p<.01, \eta_{\mathrm{p}}{ }^{2}=.05\right)$, severity of sexual bullying $\left(F_{(2,201)}=4.17\right.$, $\left.p<.05, \eta_{\mathrm{p}}^{2}=.04\right)$, willingness to intervene in physical bullying $\left(F_{(2,201)}=8.58, p<.01\right.$, $\left.\eta_{\mathrm{p}}{ }^{2}=.08\right)$, willingness to intervene in sexual bullying $\left(F_{(2,201)}=3.30, p<.05, \eta_{\mathrm{p}}{ }^{2}=.03\right)$, and willingness to intervene in indirect bullying $\left(F_{(2,201)}=3.90, p<.05, \eta_{\mathrm{p}}{ }^{2}=.04\right)$. Conceivably due to the sample size, Tukey post hoc analyses did not reveal any significant differences between the subgroups of bystanders.

\section{Discussion}

Foundational research on bully perpetration and victimization has adequately documented the pervasiveness of the bullying, and in the United States has prompted all 
50 states and the District of Columbia to enact legislation related to bullying and harassment (Maag \& Katsiyannis, 2012; Yell, Katsiyannis, Rose, \& Houchins, 2016). However, the effectiveness of these mandated legislative actions hinge on the perceptions of those who directly implement the programs. Generally, the responsibility for implementing bully prevention programs within a school context falls on school administrators and teachers. The effectiveness of these programs comes into question when students and teachers perceive and interpret the problem of bullying differently. For example, Bradshaw et al. (2007) reported that school personnel significantly underestimated the prevalence of bullying as compared to student reports.

Interpretational differences are multifaceted, because teachers may not be aware of the bullying that occurs in their classrooms (Miller et al., 1998; van Roekel et al., 2010), students may not inform teachers when it happens (Newman \& Murray, 2005), or teachers conceptualize of bullying differently than students (Beran, 2006). This study offers a glimpse into how pre-service teachers perceive the bullying dynamic. Pre-service teachers specifically were selected, as they can offer a unique perspective on bullying in that they are not far removed from their own schooling experience and yet are being prepared to understand a teacher's roles and responsibilities. Results from the current study suggest pre-service teachers believe that teacher intervention is one of the most appropriate means for decreasing bullying. Therefore, it becomes increasingly more important to understand how bullying behaviours are interpreted, how previous experiences influence these interpretations, how pre-service teachers view the severity of different topographies of bullying, and how willing they are to intervene in specific bullying scenarios to create more appropriate and effective bullying prevention policies or programs.

\section{Defining Bullying}

Overall, the pre-service teachers in this study supported the four types of bullying (verbal, indirect, physical, and sexual aggression) and four bullying characteristics as relatively important components of their definitions of bullying. Minimal differences were found between general and special education pre-service teachers with regard to ratings on types and characteristics. These findings provide insight, particularly when considering the work of Naylor et al. (2006), who found that 7th and 8th graders restricted their definitions to more direct (i.e., physical, verbal) forms of bullying, whereas classroom teachers included more specific types of bullying, including multiple forms of aggression, and mirrored the defining characteristics (i.e., imbalance of power, intent to cause harm, and repetition of behaviours; Gladden et al., 2014). Unfortunately, it is unclear why these differences in definition exist, and how differences in defining characteristics may perpetuate bullying within the schools. Therefore, it becomes important to understand preservice teachers' perceptions in order to adequately prepare them to address bullying as one of the most pressing behaviour issues among school-aged youth.

Although special and general education pre-service teachers in this study had similar bullying definitions, overall conceptualizations of bullying should include an understanding of students involved in the dynamic. While perception of student involvement remains relatively absent in the current literature, a growing body of literature suggests that students with disabilities are overrepresented within the bullying 
dynamic (see Rose et al., 2011, for review); that is, rates of bullying involvement are associated with disability status, disability characteristics, and special education services (Rose et al., 2015; Rose \& Gage, 2017). To explore this issue, our study included questions specifically about pre-service teachers' perceptions of students with disabilities' involvement in the bullying. In their survey responses, special education preservice teachers identified students with disabilities as more frequently involved in bullying (i.e., victims, bullies, fighters) than did their general education counterparts. These findings support the idea that the specialized training associated with the special education certification may uniquely qualify special educators to recognize the diverse needs and risk factors associated with certain populations of students (Syriopoulou-Delli et al., 2012). On the other hand, special education professionals may also believe the characteristics associated with specific disabilities place their students at greater risk for increased victimization or perpetration (Baker \& Donelly, 2001; Rose \& Espelage, 2012).

\section{Influential Experiences}

When describing their own experiences with bullying, respondents reported what could be viewed as fairly serious verbal scenarios that occurred in the classroom with adults present during elementary or middle school. With the exception of intent to cause physical harm, the bullying episodes they recalled fit the general definition of bullying based on the four defining characteristics. Surprisingly, pre-service teachers also believed that teacher- and student-initiated interventions would have been most appropriate in their given scenario.

While these are not novel findings (see Naylor et al., 2006), they do reinforce the importance of teacher education and intervention. Based on the current study, it was surprising to learn that the largest number of scenarios recorded instances of bullying that occurred in the classroom. Classroom teachers often underestimate the prevalence of bullying within their own classrooms (Bradshaw et al., 2007). In the United States, as states begin to adopt bully prevention legislation in combination with the National Academies of Sciences, Engineering, and Medicine (NASEM, 2016) recommending multi-component prevention approaches, teachers need to recognize behaviours both inside and outside the classroom that could be considered bullying. Although research shows that teachers are proficient at identifying students who exhibit aggressive behaviours (Huesman, Eron, Guerra, \& Crawshaw, 1994; Whitney, Smith, \& Thompson, 1994), a discrepancy exists between teacher and student nominations of classroom bullies and victims.

When conceptualizing a multi-component program (primary prevention, secondary supports, targeted interventions), in the context of responses gleaned from this study, intervention efforts should include both teacher- and student-initiated approaches. This type of multi-component approach would help teachers become more aware of bullying behaviours and allow students to take ownership of the intervention efforts (Rose et al., 2011; Rose \& Monda-Amaya, 2012). For example, Lewis and Rose (2013) offered guidance to districts, schools, and teachers by providing a school-wide action plan for bully prevention, in which they encourage schools and teachers to use data to drive the action plan, by assessing behaviours observed or reported, creating lesson plans to address these behaviours, increasing supervision in high-risk locations, identifying skill 
development strategies for victims, and creating a protocol for consequences that are tied to the school-wide expectations. Ultimately, university preparation programs must acknowledge the pervasiveness of bullying and must begin to incorporate anti-bullying approaches into the pedagogical content for all pre-service educators that parallel the school-based approaches implemented in schools.

\section{Beliefs About Intervention Efforts}

The majority of the respondents believed practising teachers could adequately identify chronic bullies and victims in their classroom. However, evidence suggests that teachers often fail to identify bullies and victims as compared with student-reported data (Bradshaw et al., 2007; Huesman et al., 1994). This discrepancy is disconcerting; if teachers continue to believe that they are correctly identifying bullies and victims, when they truly only identify a portion of those involved in the bullying, then intervention efforts will be misguided and ineffective.

Although respondents believed that teachers adequately identify bullies and victims, they rated teachers' ability to intervene much lower. Additionally, pre-service special educators rated practising teachers' ability to intervene to prevent bullying significantly lower than elementary and secondary pre-service teachers. This finding could be attributed to teachers' perceptions of bullying, given that physical bullying is traditionally rated as most severe (Ellis \& Shute, 2007; Kochenderfer-Ladd \& Pelletier, 2008). Unfortunately, this perception could be detrimental to eliminating bullying within the school setting because students believe verbal, indirect, and sexual bullying are as harmful as physical bullying and warrant intervention (Newman \& Murray, 2005). To compound this issue, any topography of victimization could result in life-long consequences (Crosby et al., 2010; Sullivan, Cleary, \& Sullivan, 2004).

In addition to teachers recognizing and intervening, school administration and policies play an integral role in eliminating bullying. According to the results of the current study, pre-service teachers believe that schools should incorporate system-wide bully prevention programs and adopt targeted intervention strategies for at-risk subgroups. Although special education pre-service teachers feel more strongly about intervention efforts, elementary and secondary education majors reported relatively high mean scores as well. These data support the basic tenets of multi-component systems, in which schools would be incorporating school-wide, classroom, and targeted interventions. While research is limited in the area of multi-component bully prevention programs (NASEM, 2016), practising teachers do view bullying as a serious problem that warrants intervention (Nicolaides et al., 2002).

\section{Bullying Severity and Willingness to Intervene}

Overall, the three groups of pre-service teachers (i.e., elementary education, secondary education, special education) did not differ in ratings on the severity or their willingness to intervene in scenarios clustered in the areas of physical, verbal, indirect, and sexual bullying. Respondents believed scenarios around sexual bullying were the most severe and they were most willing to intervene, followed by verbal, physical, and 
indirect bullying respectively. Although not statistically significant, these ratings are of interest because they contradict extant literature.

Since sexual bullying is more appropriately identified as sexual harassment (American Association of University Women Educational Foundation, 1993, 2001) and may maintain different predictive factors (Espelage, Stein, Rose, \& Elliott, 2009), much of the current literature does not include sexual bullying in its investigations.

Given the absence of sexual bullying in traditional bullying literature, students and practising teachers generally identify physical bullying as more serious than verbal or indirect forms of bullying (Bauman \& Del Rio, 2006; Ellis \& Shute, 2007; Hazler et al., 2001; Newman \& Murray, 2005). The current study, however, has supported the severity of verbal bullying and consistently identified verbal forms of aggression more prominently than physical aggression. This inconsistency may be due to the fact that practising teachers have a moral obligation to intervene in potentially harmful situations (Bauman \& Del Rio, 2006; Ellis \& Shute, 2007). The pre-service teachers in this sample did not carry this same obligation since they were not in a take-over situation in their teaching placements, nor did they have sole responsibility for a group of students. However, this outlook on the severity of verbal bullying is positive because marginalized populations of students often view teasing and indirect bullying to be as serious a problem as physical abuse (Newman \& Murray, 2005; Rose et al., 2011).

Since intervention strategies often are based on the perceptions of episode severity (Ellis \& Shute, 2007; Kochenderfer-Ladd \& Pelletier, 2008), respondents' willingness to intervene in the current study mirrored their severity ratings (i.e., sexual, verbal, physical, indirect). Generally, practising teachers believe intervention is absolutely necessary for physical forms of bullying (Newman \& Murray, 2005), but are more likely to let students work indirect bullying situations out on their own (Ellis \& Shute, 2007; Yoon \& Kerber, 2003). Unfortunately, certain subgroups of students (e.g., students with disabilities) may not possess the social or communication skills necessary to independently resolve these situations (Baker \& Donelly, 2001; Kaukiainen et al., 2002; Llewellyn, 2000; Rose et al., 2011; Woods \& Wolke, 2004).

Consequently, teachers should adopt various intervention techniques to address all forms of bullying, and these techniques can be introduced in pre-service courses and training. Kochnderfer-Ladd and Pelletier (2008) found that teachers endorsed interventions that helped students be more assertive when facing a bullying situation. According to Nicolaides et al. (2002), teachers found strategies that supported the victim and empowered bystanders were most effective for preventing bullying. However, teachers were less confident in intervening with the bully (Nicolaides et al., 2002). Unfortunately, all of these intervention methods are social constructs that require some level of social and communication skills instruction. Given the social complexities of the bullying dynamic (NASEM, 2016) teachers must incorporate social and communication skills curriculum into their daily classroom routines, which can be facilitated in their pre-service coursework. 


\section{Limitations}

While this study has attempted to fill a gap in the literature by assessing pre-service teachers' perceptions of the bullying dynamic, and has offered several important findings, there are several limitations that should be noted. First, this study used the BPS-R, which represents the first time this particular instrument has been used to assess pre-service teachers' experiences. Therefore, standardization and validity could not be established beyond the initial development and piloting of the measure. Additionally, the analytic procedure employed throughout this study was reliant on multivariate analysis of variance due to the item and scale structure of the instrument. While different constructs were examined in each MANOVA, a conflation of error rate could occur, which might increase the likelihood of type-I errors. Additional studies are needed to examine and confirm the results of the current study.

Second, this study was reliant on pre-service teachers' self-report at a single institution. Although self-report is an acceptable means of investigation, careful attention must be paid to sampling, survey items, non-respondents, and data analysis (Krathwohl, 1998). Additionally, the results should be interpreted with caution, as respondents were drawn from a single institution. The current study attempted to address these concerns, but several limitations emerged due to the use of self-report measures and a population from a single institution. For example, students from a single institution are subject to the same or similar course content, which may influence responding. Furthermore, respondents were asked to describe an incident of bullying that they either witnessed or were in some way involved. Their responses may have been recollections of incidents from some time ago, so accuracy could be in question. Additionally, their responses could have been biased, responding in a way that presented their involvement in the bullying situation, especially if they were the perpetrator, in a more positive light. However, it should be noted that these perceptions, even if biased, might influence the way they address bullying within their classrooms.

Third, and in addition to the participants attending the same institution, they were also predominantly female ( $n=196$; male, $n=26)$. While gender differences were examined both for perceptions or beliefs about bullying and for types of bullying experiences, the data may be skewed due to the disproportionate distribution of the study sample. However, education programs in the United States report a 3:1 ratio of female to male students (U.S. Department of Education, 2012).

Fourth, while a power analysis was conducted, the sample population was limited; and the limited number of participants potentially skewed the data. Sample size emerged as a problem, especially due to the limited number of males and special education preservice teachers. In addition, there is the limitation of the generalizability for these findings directly to classroom teachers. While our intention was to draw from perceptions and experiences of pre-service teachers for the purpose of influencing teacher education, it is difficult to draw conclusions without making connections to practising teachers' perceptions of bullying. 


\section{Implications}

Several educational implications emerged from this work. First, findings have direct implications for special and general education teacher preparation programs. Based on the pervasiveness of bullying, teacher preparation programs must include instruction in bully prevention and intervention integrated throughout their program, but especially in classroom and behaviour management courses. NASEM (2016) identified multicomponent programs that focus on skill development as the most promising bully prevention approaches. Therefore, novice teachers should be taught to identify bullying situations and understand the range of roles within the bullying dynamic. They should also be equipped with interventions for reducing and preventing bullying situations, including embedding social and emotional learning into the daily curriculum (Espelage, Rose, \& Polanin, 2015). These skills include self-awareness, social awareness, self-management, relationship skills, and responsible decision making (Collaborative for Academic, Social, and Emotional Learning [CASEL], 2012). Throughout their program, they should be introduced to multi-component models of bullying prevention and intervention that support the entire student body, provide targeted skills (i.e., how to recognize, respond to, and report bullying) to populations of students who are at escalated risk for involvement (e.g., students with disabilities), and empower bystanders to be active stakeholders.

Second, findings from this study point to the need for incorporating multi-component systems of support for bullying interventions, especially since pre-service teachers view school-wide interventions and targeted interventions as important. However, caution must be given to simply reframing existing programs and packaging them as bully prevention. Multi-component systems of support should incorporate a school-wide prevention program with social skills, communication skills, and bully awareness strategies embedded into the curriculum. Additionally, programs should incorporate thoughtfully planned group interventions for at-risk subpopulations of students and should provide individual supports for chronic victims and perpetrators. Most importantly, programs should support skill development for chronic bullies and victims, while empowering bystanders to become active stakeholders in the bully prevention efforts.

Finally, this study makes a strong case for increased professional development. Veteran and novice teachers must be skilled in identifying bullies and victims and providing appropriate supports. Professional development should include instruction in understanding and defining bullying, creating a classroom environment that deters bullying behaviour, incorporating an effective social skills curriculum, identifying at-risk student populations, and targeting effective intervention strategies. Additionally, teachers should be made aware of the hazards of verbal and indirect bullying, and learn to address them quickly and efficiently.

\section{Conclusion}

Bullying has emerged as one of the most fundamental problems facing schools in the United States (Hong \& Espelage, 2012; Rose et al., 2015). Since 1999, U.S. state legislators have taken a keen interest in this issue, and all 50 states have enacted legislation that prohibits bullying and harassment, and have taken measures to report policies, programs, and procedures to students and parents (Yell et al., 2016). Teachers 
must be able to competently recognize, understand, and address all forms of bullying within their classrooms. This competence is fostered at the pre-service level, when education majors are required to engage with content and practical experiences that help them develop their conceptualization of bullying behaviours. Through the educational content and experiences, pre-service teachers learn practical strategies for classroom management and bullying interventions. These strategies prompt pre-service teachers to become change agents who can impact school policies and bully intervention efforts.

\section{References}

American Association of University Women Educational Foundation. (1993). Hostile hallways: The AAUW survey on sexual harassment in America's schools (No. 923012). Washington, DC: Harris/Scholastic Research.

American Association of University Women Educational Foundation. (2001). Hostile hallways: Sexual harassment and bullying in schools. Washington, DC: Harris/Scholastic Research.

Athanasiades, C., \& Deliyanni-Kouimtzis, V. (2010). The experience of bullying among secondary school students. Psychology in the Schools, 47, 328-341.

Baker, K., \& Donelly, M. (2001). The social experiences of children with disabilities and the influence of environment: A framework for intervention. Disability \& Society, 16, 71-85.

Bandura, A. (1977). Social learning theory. Englewood Cliffs, NJ: Prentice-Hall.

Bauman, S., \& Del Rio, A. (2006). Preservice teachers' responses to bullying scenarios: Comparing physical, verbal, and relational bullying. Journal of Educational Psychology, 98, 219-231.

Beran, T. N. (2006). Preparing teachers to manage school bullying: The hidden curriculum. Journal of Educational Thought, 40, 119-128.

Bradshaw, C. P., Sawyer, A. L., \& O'Brennan, L. M. (2007). Bullying and peer victimization at school: Perceptual differences between students and school staff. School Psychology Review, $36,361-382$.

Brendtro, L. K., Ness, A., \& Mitchell, M. (2001). No disposable kids. Longmont, CO: Sopris West.

Bronfenbrenner, U. (1977). Toward an experimental ecology of human development. American Psychologist, 32, 513-531.

Bronfenbrenner, U. (1986). Ecology of the family as a context for human development: Research perspectives. Developmental Psychology, 22, 723-742.

Brownell, M. T., Ross, D. D., Colón, E. P., \& McCallum, C. L. (2005). Critical features of special education teacher preparation: A comparison with general teacher education. The Journal of Special Education, 38, 242-252.

Collaborative for Academic, Social, and Emotional Learning. (2012). 2013 CASEL guide: Effective social and emotional learning programs, preschool and elementary school edition. Chicago, IL: Author.

Crosby, J. W., Oehler, J., \& Capaccioli, K. (2010). The relationship between peer victimization and post-traumatic stress symptomatology in a rural sample. Psychology in the Schools, 47, 297310. doi:10.1002/pits

Ellis, A. A., \& Shute, R. (2007). Teacher responses to bullying in relation to moral orientation and seriousness of bullying. British Journal of Educational Psychology, 77, 649-663. 
Espelage, D. L., Rose, C. A., \& Polanin, J. R. (2015). Social-emotional learning program to reduce bullying, fighting, and victimization among middle school students with disabilities. Remedial and Special Education, 36, 299-311.

Espelage, D. L., Stein, N. D., Rose, C. A., \& Elliot, J. (2009, April). Middle school bullying \& sexual violence: Unique \& shared predictors. Paper presented at the annual meeting of the American Educational Research Association, San Diego, CA.

Farmer, T. W., Lines, M. M., \& Hamm, J. V. (2011). Revealing the invisible hand: The role of teachers in children's peer experiences. Journal of Applied Developmental Psychology, 32, 247-256.

Farmer, T. W., Petrin, R., Brooks, D. S., Hamm, J. V., Lambert, K., \& Gravelle, M. (2012). Bullying involvement and the school adjustment of rural students with and without disabilities. Journal of Emotional and Behavioral Disorders, 20, 19-37. doi:10.1177/1063426610392039

Faul, F., Erdfelder, E., Buchner, A., Lang, A. (2009). Statistical power analysis using G*Power 3.1: Tests for correlation and regression analyses. Behavior Research Methods, 41, 1149-1160.

Gladden, R. M., Vivolo-Kantor, A. M., Hamburger, M. E., \& Lumpkin, C. D. (2014). Bullying surveillance among youths: Uniform definitions for public health and recommended data elements, Version 1.0. Atlanta, GA: National Center for Injury Prevention and Control, Centers for Disease Control and Prevention, and U.S. Department of Education.

Gumpel, T. P., Zioni-Koren, V., \& Bekerman, Z. (2014). An ethnographic study of participant roles in school bullying. Aggressive Behavior, 40, 214-228.

Hazler, R. J., Miller, D. L., Carney, J. V., \& Green, S. (2001). Adult recognition of school bullying situations. Educational Research, 43, 133-146.

Hong, J. S., \& Espelage, D. L. (2012). A review of research on bullying and peer victimization in school: An ecological system analysis. Aggressive and Violent Behavior, 17, 311-322. doi:10.1016/j.avb.2012.03.003

Huesmann, L. R., Eron, L. D., Guerra, N. G., \& Crawshaw, V. B. (1994). Measuring children's aggression with teachers' predictions of peer nominations. Psychological Assessment, 6, 329-336.

Kaukiainen, A., Salmivalli, C., Lagerspetz, K., Tamminen, M., Vauras, M., Mäki, H., \& Poskiparta, E. (2002). Learning difficulties, social intelligence, and self-concept: Connections to bullyvictim problems. Scandinavian Journal of Psychology, 43, 269-278.

Kochenderfer-Ladd, B., \& Pelletier, M. E. (2008). Teachers' views and beliefs about bullying: Influences on classroom management strategies and students' coping with peer victimization. Journal of School Psychology, 46, 431-453.

Krathwohl, D. R. (1998). Methods of educational and social science research: An integrated approach (2nd ed.). Long Grove, IL: Waveland Press.

Lewis, T. J., \& Rose, C. A. (2013). Addressing bullying behavior through school-wide positive behavior supports. Arlington, VA: Council for Exceptional Children.

Llewellyn, A. (2000). Perceptions of mainstreaming: A systems approach. Developmental Medicine \& Child Neurology, 42, 106-115.

Maag, J. W., \& Katsiyannis, A. (2012). Bullying and students with disabilities: Legal and practice considerations. Behavioral Disorders, 37, 78-86.

Maunder, R. E., Harrop, A., \& Tattersall, A. J. (2010). Pupil and staff perceptions of bullying in secondary schools: Comparing behavioural definitions and their perceived seriousness. Educational Research, 52, 263-282.

Miller, T. W., Beane, A., \& Kraus, R. F. (1998). Clinical and cultural issues in diagnosing and treating child victims of peer abuse. Child Psychiatry and Human Development, 29, 21-32. 
National Academies of Sciences, Engineering, and Medicine (NASEM). (2016). Preventing bullying through science, policy, and practice. Washington, DC: National Academies Press.

Naylor, P., Cowie, H., Cossin, F., de Bettencourt, R., \& Lemme, F. (2006). Teachers' and pupils' definitions of bullying. British Journal of Educational Psychology, 76, 553-576.

Newman, R. S., \& Murray, B. J. (2005). How students and teachers view the seriousness of peer harassment: When is it appropriate to seek help? Journal of Educational Psychology, 97, $347-365$.

Nicolaides, S., Toda, Y., \& Smith, P. K. (2002). Knowledge and attitudes about school bullying in trainee teachers. British Journal of Educational Psychology, 72, 105-118.

Rose, C. A., \& Espelage, D. L. (2012). Risk and protective factors associated with the bullying involvement of students with emotional and behavioral disorders. Behavioral Disorders, $37,133-148$.

Rose, C. A., \& Gage, N. A. (2017). Exploring the involvement in bullying among individuals with and without disabilities over time. Exceptional Children, 83, 298-314.

Rose, C. A., \& Monda-Amaya, L. E. (2007). Bullying Perceptions Scale-I. Champaign, IL: University of Illinois.

Rose, C. A., \& Monda-Amaya, L. E. (2008). Bullying Perceptions Scale-Revised. Champaign, IL: University of Illinois.

Rose, C. A., \& Monda-Amaya, L. E. (2012). Bullying and victimization among students with disabilities: Effective strategies for classroom teachers. Intervention in School and Clinic, 48, 99-107. doi:10.1177/1053451211430119

Rose, C. A., Monda-Amaya, L. E., \& Espelage, D. L. (2011). Bullying perpetration and victimization in special education: A review of the literature. Remedial and Special Education, 32, 114-130.

Rose, C. A., Stormont, M., Wang, Z., Simpson, C. G., Preast, J. L., \& Green, A. L. (2015). Bullying and students with disabilities: Examination of disability status and educational placement. School Psychology Review, 44, 425-444.

Ross, S. W., \& Horner, R. H. (2009). Bully prevention in positive behavior support. Journal of Applied Behavior Analysis, 42, 747-759. doi:10.1901/jaba.2009.42-747

Ruttan, R. L., McDonnell, M., \& Nordgren, L. F. (2015). Having “been there" doesn't mean I care: When prior experience reduces compassion for emotional distress. Journal of Personality and Social Psychology, 108, 610-622.

Salmivalli, C. (2010). Bullying and the peer group: A review. Aggression and Violent Behavior, $15,112-120$.

Sharp, S., \& Smith, P. K. (1994). Understanding bullying. In S. Sharp \& P. K. Smith (Eds.), Tackling bullying in your school (pp. 1-5). New York, NY: Routledge.

Sullivan, K., Cleary, M., \& Sullivan, G. (2004). Bullying in secondary schools: What it looks like and how to manage it. London, UK: Paul Chapman Publishing.

Syriopoulou-Delli, C. K., Cassimos, D. C., Tripsianis, G. I., \& Polychronopoulou, S. A. (2012). Teachers' perceptions regarding the management of children with autism spectrum disorders. Journal of Autism and Developmental Disorders, 42, 755-768.

U.S. Department of Education, National Center for Education Statistics. (2012). National postsecondary student aid study, Washington, DC: Author. 
van Roekel, E., Scholte, R. H. J., \& Didden, R. (2010). Bullying among adolescents with autism spectrum disorders: Prevalence and perception. Journal of Autism and Developmental Disorders, 40, 63-73.

Walker, H. M., Colvin, G., \& Ramsey, E. (1995). Antisocial behavior in school: Strategies and best practices. Pacific Grove, CA: Brooks/Cole.

Whitney, I., Smith, P. K., \& Thompson, D. (1994). Bullying and children with special educational needs. In P. K. Smith \& S. Sharp (Eds.), School bullying: Insights and perspectives (pp. 213240). London, UK: Routledge.

Woods, S., \& Wolke, D. (2004). Direct and relational bullying among primary school children and academic achievement. Journal of School Psychology, 42, 135-155.

Yell, M. L., Katsiyannis, A., Rose, C. A., \& Houchins, D. E. (2016). Bullying and harassment of students with disabilities in schools: Legal considerations and policy formation. Remedial and Special Education, 37, 274-284.

Yoon, J. S., \& Kerber, K. (2003) Bullying: Elementary teachers' attitudes and intervention strategies. Research in Education, 69, 27-35.

\section{Authors' Note}

Correspondence concerning this article should be addressed to Chad A. Rose, University of Missouri, 303 Townsend Hall, Columbia, MO, 65211, U.S.A. Email: rosech@missouri.edu 